Original papers

\section{Risk factors for long-term complications in patients with type 2 diabetes, in Sri Lanka.}

1 DACL Amarasinghe, ${ }^{2} \mathrm{P}$ Fonseka, ${ }^{3}$ DJS Fernando, ${ }^{4} \mathrm{KCS}$ Dalpatadu

\begin{abstract}
Objective: To identify risk factors for longterm complications in patients with type 2 diabetes in Sri Lanka.
\end{abstract}

Methodology: An unmatched, clinic-based, case control study. Diabetic patients enrolled from randomly selected medical clinics from primary, secondary and tertiary care level hospitals were interviewed to determine possible risk factors and screened for longterm complications. 252 diabetic patients having one or more long term complications were selected as cases and 288 diabetic patients free from long term complications included as controls.

Results: Peripheral diabetic neuropathy $(25.2 \%)$, micro albuminuria $(22.8 \%)$, retinopathy $(20 \%)$, and coronary heart disease $(12.4 \%)$ were some complications present among cases. $21.9 \%$ had only one complication while $16.5 \%$ and $6.9 \%$ had two and three complications respectively. Only $1.5 \%$ had all four complications.

In the univariate analysis, smoking, low family income, body mass index over 25 , older age ( over 60 years), longer duration of diabetes (11 -15 years), random blood sugar $>$ $11.0 \mathrm{mmol} / 1$, raised diastolic blood pressure $>$ $90 \mathrm{mmHg}$ were significantly $(\mathrm{p}<0.05)$ associated with the development of long-term complications. The latter four factors were significantly associated with a number of complications. Multivariate analysis identified older age $(\mathrm{OR}=5.51 \mathrm{CI} 1.59,19.17)$, duration of diabetes $(\mathrm{OR}=2.08 \mathrm{CI} 1.23,3.50)$, random blood sugar $11.0-16.7 \mathrm{mmol} / \mathrm{l}(\mathrm{OR}=$ $3.15 \mathrm{CI} 1.31,7.56)$ and current smoking $(\mathrm{OR}=$ 8.88 , CI $1.53,51.53$ ) as significant risk factors.

\footnotetext{
1, ${ }^{4}$ Management Development \& Planning Unit, Dept of Health Services.

${ }^{2}$ Dept. of Community Medicine, University of Ruhuna.

${ }^{3}$ Dept. of Medicine, University of Sri Jayawardanepura.
}

Conclusion: Long-term complications in type 2 diabetes are common among patients. Most of the significant risk factors are preventable.

Key Words: Type 2 diabetes, long-term complication, risk factors, clinic based

\section{Introduction}

The early detection and identification of the risk factors contributing to the development of longterm complications in diabetes is an important strategy to minimize the human suffering and costs of the conditions (1). There are several factors related to person characteristics, clinical variables and the delivery of care that play an important role in the development of complications (2). Most of these risk factors are considered as avoidable. Poor compliance, uncontrolled diet and lack of knowledge on disease are also associated with an increased risk of development of complications (2). Cigarette smoking is a well-established risk factor for the progression of diabetic complications, where as an association with alcohol consumption is not very clear $(1,2)$. Type of diabetes, duration, glycaemic control and uncontrolled hypertension are the strongest clinical predictors of the outcome $(3,4)$.

Diabetes currently afflicts more individuals than some of the communicable diseases in Sri Lanka and it has now emerged as a major public health problem. The National Diabetic Association estimates that there are one million people with diabetes in Sri Lanka (5). Studies done in Sri Lanka have reported that long-term complications are an emerging problem in this country $(6,7)$.

There appear to be challenges in the management of diabetes and its complications in Sri Lanka viz. increasing prevalence, uncertainties in risk factors of diabetes complications in our settings, and limited health care facilities on screening and management of diabetes complications. Therefore, this study was undertaken to investigate the relationship of long-term complications with some selected risk factors amongst patients with type 2 diabetes.

\section{Method}

This was a clinic based cross sectional study, designed as an unmatched case control study. This study was carried out during the period of 1998 1999 in the Western Province of Sri Lanka. Primary, secondary and tertiary level government institutions with diabetic clinic facilities were 
Table 1 : Univariate analysis

\begin{tabular}{|c|c|c|c|c|c|c|}
\hline \multirow{3}{*}{$\begin{array}{l}\text { Socio-demographic } \\
\text { Characters }\end{array}$} & \multicolumn{2}{|c|}{ Case } & \multicolumn{2}{|c|}{ Control } & \multirow{3}{*}{$\begin{array}{l}\text { Odds } \\
\text { Ratio }\end{array}$} & \multirow{3}{*}{$\begin{array}{c}\text { C.I. } \\
\text { at } 95 \%\end{array}$} \\
\hline & n & $\%$ & n & $\%$ & & \\
\hline & \multicolumn{2}{|c|}{$(n=252)$} & \multicolumn{2}{|c|}{$(n=288)$} & & \\
\hline \multicolumn{7}{|l|}{ Age } \\
\hline Below 40 yr. & 5 & 1.9 & 24 & 8.4 & 1.00 & \\
\hline $40-60 \mathrm{yr}$ & 112. & 44.5 & 155 & 53.8 & 3.47 & $(1.24,11.96)$ \\
\hline Over $60 \mathrm{yr}$. & 135 & 53.6 & 109 & 37.8 & 5.94 & $(2.12,20.49)$ \\
\hline \multicolumn{7}{|l|}{ Income (Rs) } \\
\hline$<2500$ & 126 & 50.0 & 112 & 38.9 & 1.00 & \\
\hline $2500-5000$ & 75 & 29.8 & 117 & 40.6 & 0.57 & $(0.38,0.85)$ \\
\hline$>5000$ & 51 & 20.2 & 59 & 20.5 & 0.77 & $(0.48,1.24)$ \\
\hline \multicolumn{7}{|l|}{ Continues treatment } \\
\hline Yes & 195 & 77.4 & 232 & 80.6 & 1.00 & \\
\hline *No & 57 & 22.6 & 56 & 19.4 & 1.21 & $(0.78,1.87)$ \\
\hline \multicolumn{7}{|l|}{ Smoking } \\
\hline Non-Smokers & 215 & 85.3 & 258 & 89.6 & 1.00 & \\
\hline Ex-smokers & 13 & 5.2 & 22 & 7.6 & 0.71 & $(0.33,1.51)$ \\
\hline Current smokers & 24 & 9.5 & 8 & 2.8 & 3.6 & $(1.50,8.90)$ \\
\hline \multicolumn{7}{|l|}{ Alcohol } \\
\hline Non- alcoholic & 219 & 86.9 & 242 & 87.5 & 1.00 & \\
\hline Ex-drinker & 16 & 6.4 & 15 & 5.2 & 1.17 & $(0.56,2.69)$ \\
\hline Current drinker & 17 & 6.8 & 21 & 7.3 & 0.89 & $(0.46,1.90)$ \\
\hline \multicolumn{7}{|l|}{ Disease Duration } \\
\hline 5.10 Years & 196 & 77.8 & 248 & 86.1 & 1.00 & \\
\hline $11-15$ years & 35 & 13.9 & 23 & 7.9 & 1.93 & $(1.07,3.49)$ \\
\hline$>15$ years & 21 & 8.3 & 17 & 6.0 & 1.56 & $(0.77,3.20)$ \\
\hline \multicolumn{7}{|l|}{ RBS (mnoLl) } \\
\hline$<11.0$ & 131 & 52.0 & 204 & 70.8 & 1.00 & \\
\hline $11.0-16.7$ & 90 & 35.7 & 58 & 20.1 & 2.42 & $(1.85,7.90)$ \\
\hline$>16.7$ & 31 & 13.3 & 26 & 9.1 & 1.86 & $(1.24,6.86)$ \\
\hline \multicolumn{7}{|l|}{ Systolic BP $(\mathrm{Hg} \mathrm{mm})$} \\
\hline$<160$ & 198 & 78.6 & 235 & 81.6 & 1.00 & \\
\hline 160 or above & 54 & 21.4 & 53 & 18.4 & 1.26 & $(0.80,2.00)$ \\
\hline \multicolumn{7}{|l|}{ Diastolic BP (Hg mm) } \\
\hline$<90$ & 131 & 52.0 & 176 & 61.1 & 1.00 & \\
\hline 90 or above & 121 & 48.0 & 112 & 38.9 & 1.45 & $(1.02,2.07)$ \\
\hline \multicolumn{7}{|l|}{ BMII } \\
\hline$<25$ & 14 & 5.6 & 32 & 11.1 & 1.00 & \\
\hline $25-27$ & 143 & 56.7 & 151 & 52.4 & 2.16 & $(1.07,4.57)$ \\
\hline$>27$ & 95 & 37.7 & 105 & 36.5 & 2.07 & $(1.00,4.45)$ \\
\hline \multicolumn{7}{|l|}{ Cholesterol ( $\mathrm{mmol} / \mathrm{l})$} \\
\hline$<6.2$ & 172 & 68.4 & 202 & 70.2 & 1.00 & \\
\hline 6.2 or more & 80 & 31.6 & 86 & 29.8 & 0.92 & $(0.78,4.48)$ \\
\hline
\end{tabular}

* No Treatment continuity - Off oral glucaemic treatment $>3$ months, without medical advice 
Table 2: Logistic regression analysis. Outcome variable - long-term complication(s) Vs none

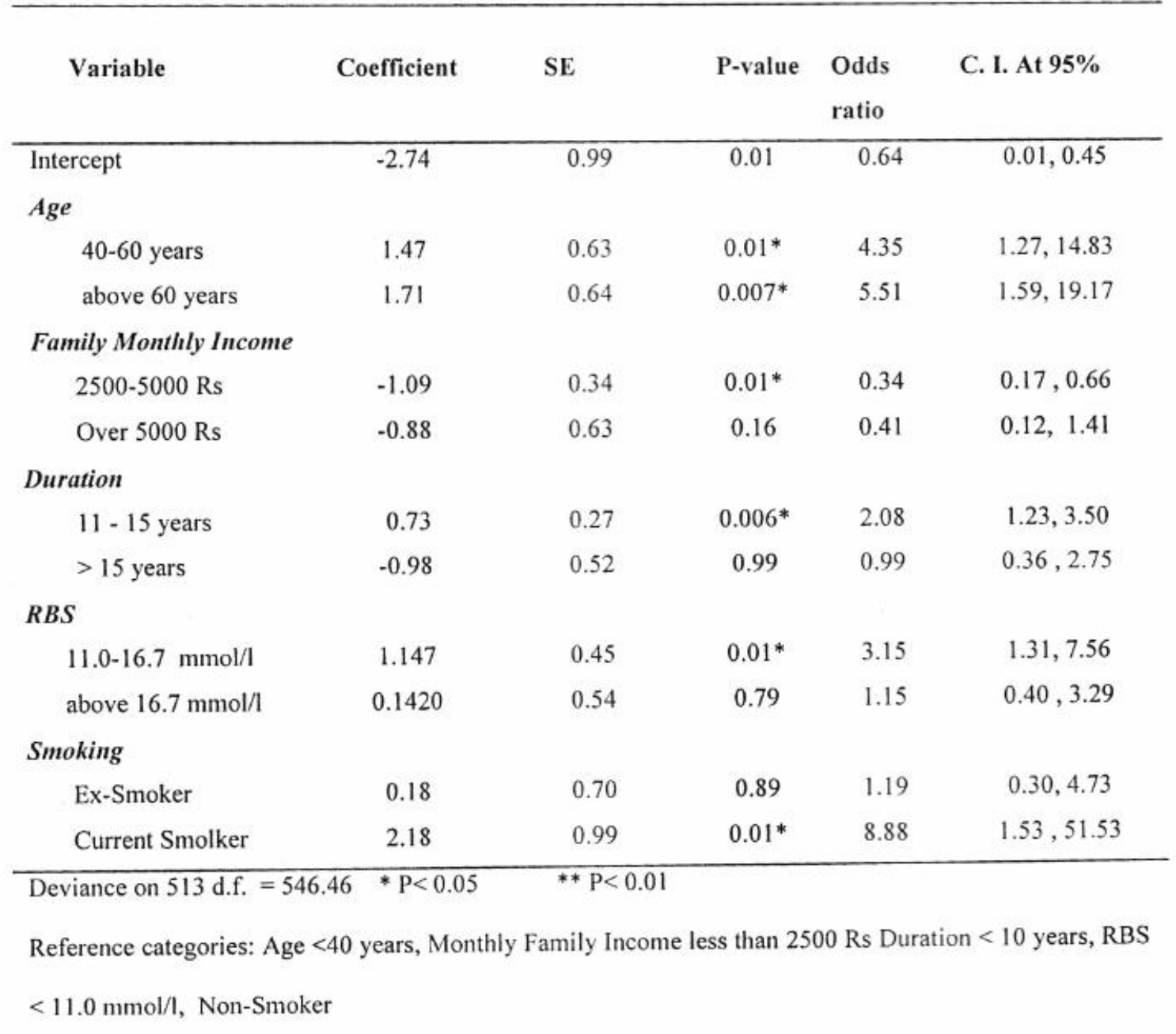


selected as study centres using the simple random sampling method.

A case was defined as a patient attending clinic and diagnosed as type 2 diabetes for a period of 5 years and newly identified with one or more of the following long-term complications during the survey: diabetic retinopathy (by direct ophthalmoscopy after pupillary dilation and the presence of microaneurysms, haemorrhages, cotton wool spots, microvasular abnormalities. Exudates were not considered, because they were not specific for diabetes.) (8); peripheral diabetic neuropathy ( the insensitivity to the $5.07 \mathrm{~g}$ monofilament at one or more of nine sites on either foot) (9); diabetic nephropathy ( presence of microalbuminuria, 20 to $200 \mathrm{mg} / \mathrm{l}$, in two consecutive urine collections) (10);: Coronary heart diseases ( based on ECG records: coronary probable, coronary possible and normal, according to Minnesota coding system) (11).

Controls were patients attending the diabetic clinic and diagnosed as type 2 diabetes for a period of 5 years, but free from long-term complications at the time of screening.

Patients, who were diagnosed as type 2 diabetes, within last five years and were under treatment or treated for the complications or/and risk factors being studied, as well as pregnant women and those who did not cooperate for any reason were excluded.

The sample size was calculated with sufficient power $(90 \%)$ to detect effects with a $95 \%$ confidence interval. Selection of cases and controls was done by enrolling all consecutive cases and controls screened from the eligible diabetic patients. This sample size included $10 \%$ guard against non-response and $30 \%$ for confounding variables.

At the preliminary stage nearly 700 eligible subjects were identified. They were invited to a special screening clinic and 570 responded. Following the screening, 252 respondents were identified as cases and 288 as controls.

World Health Organization (WHO) recommended guidance was used to check the blood pressure (BP). A standard mercury sphygmomanometer was used with a $23 \mathrm{x}$ $14 \mathrm{~cm}$ cuff (bladder $23 \times 13 \mathrm{~cm}$ ) and a larger cuff for obese patients. Precision- G Glucometer/ Medi Sense-2 blood glucose test strips were used to detect random blood sugar
(RBS) and Micral Test II strips to test urine microalbuminuria (MA). Twelve lead resting electrocardiograms (ECG) were taken and coded by the Minnesota codes (11). The patient's clinic records were also used to abstract the information on patient's disease status. The patients were interviewed to obtain relevant information for the study.

Preliminary univariate analysis identified that many factors are significantly associated with the risk of long-term complications. Since the long-term complications have many possible outcome variables and the study design was an un-matched case control study, a logistic regression model was used (EGRET software) with the forward selection procedure.

\section{Results}

Peripheral diabetic neuropathy $(25.2 \%)$ was the commonest complication among the study population, where as the coronary heart disease (12.4\%) was the least common. Diabetic retinopathy and diabetic nephropathy / MA were $20.0 \%$ and $22.8 \%$ respectively. $21.9 \%$ had one complication, while only $1.5 \%$ had all the complications. $16.5 \%$ and $6.9 \%$ respectively had two and three complications.

\section{Person factors}

Elderly age and lower monthly family income were statistically significant $(\mathrm{P}<0.05)$ socio-demographic characters associated with the development of long-term complications, (Table 1). Older age of over 60 years had nearly a six fold increased risk. The patients who had discontinued treatment also had greater risk of developing long term complications.

Smoking $(\mathrm{p}<0.01)$ was the only other significant person risk factors found in the present study. A 3.6 fold increased risk of long-term complications was seen among current smokers. The mean duration of diabetes and amount of smoking between current and ex-smokers were also assessed. Both mean duration and amount smoked for current smokers were significantly $(\mathrm{p}<0.001)$ higher for cases than for the controls. However, the difference with mean smoking duration and the difference with the mean number of cigarettes/day of ex smokers among cases and controls were not statistically significant $(\mathrm{p}>0.05)$.

\section{Clinical variables}

The risk of development of long-term complications increased with the duration of diabetes (Table $1 \&$ 2) up to 15 years. Beyond 15 years this risk decreased with longer duration. High RBS level over $11 \mathrm{mmol} / \mathrm{l}$ was significantly 
$(\mathrm{p}<0.01)$ associated with the development of long-term complications (Table 1\& 2). A three times increased risk of developing longterm complications for subjects with random blood sugar level of $11.0-16.7 \mathrm{mmol} / 1$ was observed. When the RBS level was more than $16.7 \mathrm{mmol} / 1$, this risk was reduced. However at higher level of RBS $(>16.7 \mathrm{mmol} / \mathrm{dl})$, they had more significant $(\mathrm{p}<0.005)$ tendency to have more number of complications.

Arterial hypertension was defined according to the ADA and WHO criteria: systolic BP > $160 \mathrm{~mm} \mathrm{Hg}$ or diastolic BP $>90 \mathrm{~mm} \mathrm{Hg}$ (12). The mean systolic BP for cases and controls was $142.4 \mathrm{mmHg}$ and $139.7 \mathrm{mmHg}$ respectively, while the mean diastolic BP among cases and contróls were respectively $86.7 \mathrm{mmHg}$ and $84.8 \mathrm{mmHg}$. Both high systolic and high diastolic BP are associated with a higher risk of developing long-term complications $(2,4)$. In this study however only raised diastolic blood pressure was statistically significant $(p=0.03)$. Neither systolic $(\mathrm{p}=0.75)$ nor diastolic $(\mathrm{p}=0.61)$ blood pressures was statistically significantly associated with the number of complications in type 2 diabetes.

There is a twofold increase in the risk of complications when body mass index (BMI) is more than 25. The level of serum cholesterol was statistically not significantly $(\mathrm{P}>0.05)$ associated with complications in type 2 diabetes. The patients with high level of serum cholesterol $(>6.2 \mathrm{mmol} / \mathrm{l})$ was at a lower risk, compared to the lower serum cholesterol of less than $6.2 \mathrm{mmol} / 1$. There was no statistically significant association ( $>0.05)$ between the level of serum cholesterol and the number of long-term complications.

\section{Discussion}

Diabetes, once thought to be a disease of affluent countries, has emerged as a public health concern in the developing countries, including Sri Lanka. The age adjusted (30 -65 years) crude prevalence of diabetes for the adult population in Sri Lanka is around 5\% (5). In Sri Lanka, patients are able to visit any government health facility they chose. The majority of the study population was female, above the age of 40 years, and from low income groups. This is expected as the majority of working men with diabetes are likely to receive their diabetes care privately.
Thus the findings of this study are generalisable to the patients receiving care in government clinics, but may not apply to those receiving private care. This was one of the limitations in the present study.

\section{Person related risk factors}

As reported in earlier studies in many parts of the world, this study also identified that persons of older age over 60 years and low income groups are at higher risk for the development of long-term complications $(2,13)$. Increased risk of developing long-term complications at an older age is inevitable, because early onset of diabetes leads to a longer duration of the illness. Even after controlling for these confounding effects, age was a highly significant risk factor in developing longterm complications in type 2 diabetes.

Continuity of treatment is an important factor in controlling or preventing any disease. This may be affected by many other factors such as, severity of the disease, remissions, use of other traditional methods, ignorance etc. This study identified that discontinuity of treatment had a higher risk of developing long-term complications. Studies done in Sri Lanka and abroad had reported the importance in continuity of treatment in the prevention and control of complications in diabetes and therefore the importance of continuous

treatment should be highlighted in the management of long-term complications $(6,13,14)$.

Effects of smoking on diabetes and long-term complications are well known and established (1, 2 ). This study too revealed similar findings. It was interesting to note, that heavy smokers had a relatively lower risk than average smokers. The possible reason is survival of average smokers than the heavy smokers. In this study, the inverse association between alcohol consumption and longterm complications was established. Orchard et al described, that there was no evidence of long-term alcohol intake and dose response relationship in developing long-term complications. In fact they revealed an inverse relationship between alcohol and glycaemia (13). Both smoking and alcohol are predominantly seen in males in Sri Lanka. In this study females accounted for $80 \%$ of the study population. As only a small number of males were included, the results should be interpreted with caution. 


\section{Clinical risk factors}

Duration of diabetes, poor $\mathrm{GC}$, raised $\mathrm{BP}$, high level of cholesterol and BMI are established risk factors for complications of diabetes $(2,4,6,13)$. This study also revealed similar findings except in cholesterol: two fold increased risk with long duration of diabetes (11-15 years) and higher RBS over $11.0 \mathrm{mmol} / \mathrm{l}$ and, BMI over 25 . Also all these were statistically significant $\quad(\mathrm{p}<0.01)$. Although, the patients with recorded high systolic (>160 $\mathrm{mm} \mathrm{Hg}$ ) and high diastolic (>90 $\mathrm{mm} \mathrm{Hg}$ ) blood pressure were found to be at higher risk of developing long-term complications, it was observed that only raised diastolic blood pressure was significant as a risk factor for diabetic complications. Other studies have reported possible risk of either one or both systolic and diastolic blood pressure in complications of diabetes $(4,15,16)$.

However interestingly, longer duration of diabetes (over 20 years), very high level of RBS ( $>16.7 \mathrm{mmol} / \mathrm{l})$, raised cholesterol $(>6.2 \mathrm{mmol} / \mathrm{l})$ and high BMI $(>27)$ showed a decreasing trend of risk in the present study, which is contrary to the findings of the studies carried out in other countries $(3,13)$. The observed lower risk of complications in those with longer duration of diabetes, very high level of RBS is probably a function of a relative survival.

The two major limitations in this study were; (i) non-use of more advance techniques to screen some diabetic complications (HbAs for glycaemic control and Neurothesiometer to detect diabetic neuropathy), these may cause some misclassification of disease status (ii) risk factors were studied for all complications together, but not separately for each complication. Using more advanced techniques in screening and studying a large sample for each complication would have been ideal, but could not be carried out due to practical and other logistic constraints.

In conclusion, our findings suggest that longterm complications in type 2 diabetes are important health problems among patients attending state sector clinics in Sri Lanka. Most of the identified risk factors are preventable. It is obvious with the increase of incidence and prevalence of diabetes, longterm complications of diabetes will tend to rise. Hence, strategy will be plan and implement 'risk factors' oriented preventive programmes. Widespread coverage of basic investigation facilities and centres of excellence with advanced techniques for diagnosis of longterm complications should also be established. Further studies are needed in the field of epidemiology of long-term complications of diabetes.

\section{Acknowledgment}

This study was supported by a grant from the Asian Development Bank. Grateful thanks to Dr. D.D.H.Wariyapola and Dr. $\mathrm{H}$ Palihakkara Consultant eye surgeons, Dr. Hemantha Peries, Senior lecturer Dept. of Biochemistry, University of SriJayawardanepura, Sri Lanka, Dr. Roshini Sooriyarachchi, Consultant statistician, Dr Ruwan Wijesuriya and Dr Mayura de Silva Medical Officers, Ranjith de Silva and Niranjala Madanasinghe statisticians for their extensive contribution.

\section{References}

1. Prevention of diabetes mellitus. WHO Technical Report Series. No 844, 1994.

2. Nicolucci A, Cavaliere D, Scorpiglione N, et al. A comprehensive assessment of the avoidability of long-term complications of diabetes. Diabetes Care. 1996; 19 (9): 927- 933.

3. Dupree EA, Meyer MB. Role of risk factors in complications of diabetes mellitus. American Journal of Epidemiology. 1980; 112: 100-112.

4. Schrier RW, Estacio RO, Jeffers B. Appropriate Blood Pressure Control in NIDDM (ABCD) Trial: Clinical trial design. Diabetologia. 1996; 39: 16461654 .

5. Wijesuriya M. Prevalence of diabetes in Sri Lanka. International Journal Diabetes in Developing Countries. 1997; 17: 1-4.

6. Fernando DJS, Siribaddana S, De Silva, Subasinghe Z. Prevalence of retinopathy in a Sri Lankan diabetic clinic. Ceylon Medical Journal. 1993; 38: 120-123.

7. Weerasuriya $\mathrm{N}$, Siribaddana $\mathrm{S}$, Dissanayake A, et al. Long-term complications in newly diagnosed Sri 
Lankan patients with type 2 diabetes mellitus. QJ Med. 1998; 91: 1-5.

8. American Diabetes Association. Position Statement: Diabetic retinopathy. Diabetes Care. 1998; 21: Suppl.1.

9. Maser RE, Orchard TJ. Diabetic Neuropathy: Its measurement and epidemiologic features. Del Med Journal. 1991; 63(2): 85-93.

10. Ellis D, Lloyd CE, Becker DJ , KimberlyYF, Orchrad TJ. The changing course of diabetic nephropathy. American Journal of Kidney Diseases. 1996; 27 (6): 809818.

11. Prieas RJ, Crow RS. Blackburn H. The Minnesota Code Manual of Electrocardiographic Finding: Standards, Procedures for Measurement and Classification. John Wright. Bristol. 1962.

12. American Diabetes Association. Position Statement: Clinical practice recommendations. Diabetes Care. 1998; 21 Supplement 1.

13. Orchard TJ, Dorman JS, D'Antonio JA, et al. The natural history of diabetes complications: The Pittsburgh Studies. Journal of Medical Association, Thailand. 1987; 70(2): 153-162.

14. Nimalasuriya A, Mihindukulasuriya CJ, Weerasinghe WMT. A Study of the pattern of diabetes mellitus and its control at the diabetic clinic, General Hospital Colombo. Proceeding of Annual Sessions of the Sri Lanka Association of the advancement of Science. 1977; 1: 89.

15. Mohan V, Vijayaprabha R, Rema M. Vascular complications in long-term South Indian NIDDM of over 25 years duration. Diabetes Research and Clinical Practice. 1996; 31: 133140.
16. Keen $H$, Jarrett RJ. The WHO multinational study of vascular diseases in diabetes; Macrovascular diseases. Diabetes Care. 1979;2:187-195. 